\section{Indian National Science Academy}

Bahadur Shah Zafar Marg, New Delhi 110002

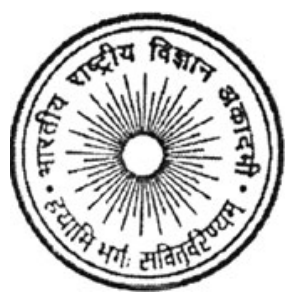

\section{CALL FOR NOMINATIONS}

INSA MEDAL FOR YOUNG SCIENTISTS-2014

Since 1974, the Academy has instituted INSA Medal for Young Scientists with the aim of recognizing young scientists of extraordinary promise and creativity who have made notable research contributions in science and technology. This award, considered to be the highest recognition of promise, creativity and excellence in a young scientist, is made annually to those distinguished for these attributes as evidenced by their research work carried out in India. Only those born on or after January 1, 1979 are eligible for consideration in the year 2014.

The awardee shall receive a certificate, a bronze medal, cash award of Rs. 25,000/- and seed amount to initiate research project and further scope for overseas training for advancement of career.

A candidate may be proposed by a Fellow of the Indian National Science Academy or by earlier recipients of this award. Scientific societies of national standing, university faculty, post-graduate department or research institutions may also make nominations of eligible candidates.
Nomination proforma can be downloaded from website www.insaindia.org/. One hard copy and a soft copy (in MS-Word only) of the nomination, along with all supporting documents, must reach the Academy latest by October 31, 2013. 